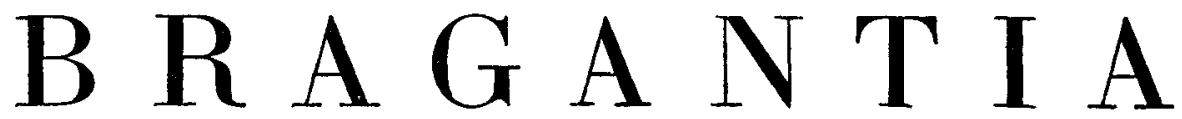

Boletim Científico do Instituto Agronômico do Estado de S. Paulo

Vol. 31

Campinas, março de 1972

N. ${ }^{0} 11$

\title{
EFEITO DE DIFERENTES FERTILIZANTES NITROGE- NADOS NA PRODUÇÃO DO TRIGO EM VASOS $\left(^{1}\right)$
}

Hermano Gargantini $\left({ }^{2}\right)$ e Francisco Solano de Oliveira FiLHo, engenheiros-agrônomos, Seção de Fertilidade do Solo, Instituto Agronômico

\section{SINOPSE}

Estudou-se a influência do sulfato de amônio, do salitre-do-chile e da uréia no desenvolvimento e na prođução do trigo, em vasos, em casa de vegetação, empregando-se um Latossolo Vermelho Escuro orto, do município de Itapetininga, Estado de São Paulo. Os resultados indicaram que, para produção de matéria seca, não houve diferença entre os fertilizantes utilizados, porém para produção đe grãos o sulfato de amônio foi o mais eficiente.

\section{1 - INTRODUÇÃO}

Numerosas pesquisas têm sido conduzidas em países tritícolas $(3,4,7,8)$ e também no Brasil $(\mathbf{1}, \mathbf{9}, \mathbf{1 1})$, sobre a importância e os efeitos dos nutrientes nitrogênio, fósforo e potássio. Trabalhos de Gargantini e colaboradores (6) mostraram que o fósforo possui capital efeito no desenvolvimento e na produção do trigo. $\mathrm{O}$ nitrogênio secunda-o nesse efeito, porém não influencia marcantemente na produção de massa verde, enquanto o potássio mostrou resposta muito pequena. Ensaios de Blanco e colaboradores (2) mostraram as respostas da cultura às aplicações de fertilizantes nitrogenados, fosfatados e potássicos, afirmando que solos que possuírem teores de nitrogênio total acima de $0,10 \%$ não apresenta-

( $)$ Trabalho parcialmente financiado pelo convênio BNDE/CIA. Recebido para publicação em $10^{\circ}$ de setembro de 1971.

$\left(^{2}\right)$ Com bolsa de suplementação do $\mathrm{CNPq}$. 
rão resposta às aplicações de adubos nitrogenados. Outros ensaios, conduzidos por Torres (11), no Estado do Rio Grande do Sul, onde foram feitas competiçães entre salitre-do-chile e sulfato de amônio, mostraram que na produção de grãos não foi observada diferença entre os dois fertilizantes estudados. Pilczer e colaboradores (9) também verificaram esse mesmo efeito, em 19 ensaios conduzidos no Estado de Santa Catarina.

Com o objetivo de estudar a competição entre várias formas de fertilizantes nitrogenados no desenvolvimento e na produção do trigo, foi realizado o ensaio aqui relatado.

\section{2 - MATERIAIS E METODOS}

$\mathrm{O}$ experimento foi conduzido em vasos de Mitscherlich, em casa de vegetação, com um Latossolo Vermelho Escuro orto, retirado dos $20 \mathrm{~cm}$ superficiais, no município de Itapetininga. O solo foi seco, bem homogenizado, e passado através de peneira de $2 \mathrm{~mm}$ de abertura de malha. Analisado segundo os métodos da Seção de Fertilidade do Solo, Instituto Agronômico, apresentou as seguintes características químicas:

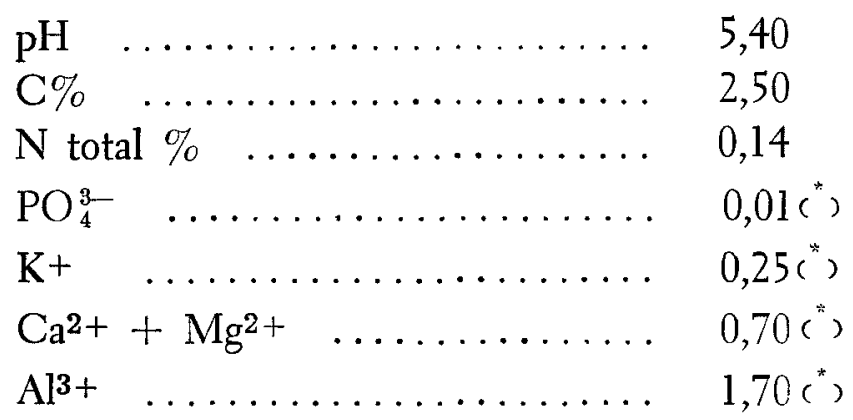

Como o solo apresentasse acidez nociva, representada pela presença do alumínio trocável, todos os tratamentos receberam calcário dolomítico, em quantidade correspondente ao teor de alumínio multiplicado pelo fator 1,5 , o que correspondeu à quantidade de $2,5 \mathrm{t} / \mathrm{ha}$. $\mathrm{O}$ calcário foi intimamente misturado com o solo, que foi a seguir umedecido, para facilitar a ação do corretivo. 
Os tratamentos estudados, com repetições ao acaso, foram:

$\begin{array}{llll}\text { 1. } & 0 & 0 & 0 \\ \text { 2. } & 0 & \mathrm{P} & \mathrm{K} \text { - sem nitrogênio } \\ \text { 3. } & \mathrm{N}_{1} & \mathrm{P} & \mathrm{K} \text { - salitre-do-chile } \\ \text { 4. } & \mathrm{N}_{2} & \mathrm{P} & \mathrm{K} \text { - salitre-do-chile } \\ \text { 5. } & \mathrm{N}_{1} & \mathrm{P} & \mathrm{K} \text { - sulfato de amônio } \\ \text { 6. } & \mathrm{N}_{2} & \mathrm{P} & \mathrm{K} \text { - sulfato de amônio } \\ \text { 7. } & \mathrm{N}_{1} & \mathrm{P} & \mathrm{K} \text { - uréia } \\ \text { 8. } & \mathrm{N}_{2} & \mathrm{P} & \mathrm{K} \text { - uréia }\end{array}$

Com exceção da testemunha, os demais tratamentos receberam adubação igual e uniforme, por vaso, de superfosfato simples e cloreto de potássio, nas quantidades de $3 \mathrm{~g}$ e $1 \mathrm{~g}$ de $\mathrm{P}_{2} \mathrm{O}_{5}$ e $\mathrm{K}_{2} \mathrm{O}$, respectivamente. Os fertilizantes nitrogenados utilizados foram $\mathrm{o}$ salitre-do-chile, o sulfato de amônio e a uréia, nas dosagens de $1 \mathrm{~g}$ e 2 g de nitrogênio, por vaso.

Em abril de 1970, treze dias após a calagem, adubaram-se os vasos e procedeu-se ao plantio. A técnica empregada para evitar o contato das sementes com os adubos foi a seguinte: retiraram-se os $5 \mathrm{~cm}$ superficiais de terra dos vasos e misturaram-se os adubos com o solo da parte inferior (aproximadamente $2 / 3$ ), que então foi retornada aos vasos. A seguir, foram distribuídas em cada vaso 15 sementes de trigo, variedade IAS-12, que foram cobertas com o restante da terra superficial. A germinação foi excelente. Após 22 dias, procedeu-se ao desbaste, para 7 plantas por vaso. $O$ ensaio transcorreu normalmente, com ótimo desenvolvimento das plantas. Verificaram-se ataques de pulgões e lagartas, que foram prontamente controlados, não tendo causado dano às plantas. $O$ suprimento de água foi feito de acordo com a recomendação de Ferreira $(\mathbf{5})$.

$\mathrm{Na}$ ocasião da colheita, em agosto, as plantas, já completamente maduras, foram cortadas rente ao solo, secas em estufa a $60^{\circ} \mathrm{C}$, sendo então pesadas as produções de matéria seca e de grãos. 


\section{3 - RESULTADOS E DISCUSSÃO}

Os dados de matéria seca e de grãos constam do quadro 1 .

Quadro 1. - Prcduções médias, por vaso, de matéria seca e de grãos de trigo, obtidas em ensaio de competição de fertilizantes nitrogenados, em Latossolo Vermelho Escuro orto, em casa de vegetação

\begin{tabular}{|c|c|c|}
\hline \multirow{2}{*}{ Tratamento } & \multicolumn{2}{|c|}{ Produção média por vaso } \\
\hline & Matéria seca & Grãos \\
\hline & g & g \\
\hline $1.000 \ldots \ldots \ldots \ldots \ldots \ldots \ldots$ & 10,25 & 0,50 \\
\hline 2. $\quad$ O $\quad P \quad K \ldots$ & 21,62 & 5,50 \\
\hline 3. $\mathrm{N}_{1} P \mathrm{~K}$ salitre-do-chile $\ldots \ldots \ldots$ & 44,13 & 7,13 \\
\hline 4. $\mathrm{N}_{2} \mathrm{P} \mathrm{K}$ salitre-do-chile $\ldots \ldots \ldots$ & 42,62 & 5,66 \\
\hline 5. $\mathbf{N}_{1} \mathbf{P} \mathbf{K}$ sulfato de amônio $\ldots$. & 46,62 & 15,33 \\
\hline 6. $\mathrm{N}_{2} P \mathrm{~K}$ sulfato de amônio $\ldots .$. & 41,87 & 11,37 \\
\hline 7. $\mathbf{N}_{1} \mathbf{P}$ K uréia $\ldots \ldots \ldots \ldots \ldots$ & 47,50 & 9,13 \\
\hline 8. $\mathbf{N}_{2} \mathrm{P} \mathbf{K}$ uréia $\ldots \ldots \ldots \ldots \ldots \ldots$ & 47,87 & 7,37 \\
\hline d.m.s. & 11,26 & 3,07 \\
\hline
\end{tabular}

Pelo exame dos resultados verifica-se que ocorreu boa reação da planta à aplicação dos fertilizantes nitrogenados. Observa-se também que até o nível 1 de nitrogênio, ou seja, $1 \mathrm{~g}$ por vaso, houve aumento de produção, e quando a dose foi elevada para $2 \mathrm{~g}$ por vaso as produções decresceram, fato, aliás, já observado por Gargantini e colaboradores (6). A análise do solo utilizado no ensaio revelou o teor de $0,14 \%$ de nitrogênio total, e mesmo assim os acréscimos de produção foram bastante sensíveis, contrariando as observações de Blanco e colaboradores (2), que, para o mesmo grande grupo Latossolo Vermelho Escuro orto, concluiram que o trigo não apresentava resposta à adubação nitrogenada quando no solo havia acima de $0,10 \%$ de $\mathrm{N}$. 
$\mathrm{Na}$ produção de matéria seca, verificou-se que a influência do nitrogênio foi muito grande, apresentando os vasos que receberam esse nutriente mais de $100 \%$ de aumento, em relação ao nível 0 , independentemente da forma do fertilizante utilizado. Também na produção de massa seca foi observado que a dose 2 dos nitrogenados provocou redução de produção, em relação ao nível 1.

Com referência à produção de grãos, o efeito dos nitrogenados também foi muito grande, mas as diferenças entre as formas dos fertilizantes se fizeram sentir. Os tratamentos que receberam adubação com salitre-do-chile foram os de menores produções, pouco acima da testemunha relativa, que recebeu somente fósforo e potássio. A utilização da uréia na adubação do trigo provocou bom aumento de produção, bem acima do verificado pelo uso do salitre, porém ainda assim abaixo do produzido pelo sulfato de amônio, cujo aumento atingiu números da ordem de $6,20 \mathrm{~g}$ por vaso mais que a uréia, e $9,67 \mathrm{~g}$ por vaso, para o tratamento com salitre-do-chile. A diferença entre a uréia e o salitre foi de $3,47 \mathrm{~g}$ por vaso, a favor da primeira. Estes resultados, submetidos à análise estatística, mostraram que houve diferença significativa entre os tratamentos: o sulfato de amônio foi diferente de todos os outros, enquanto a uréia foi superior ao salitre-do-chile, e este não diferiu da testemunha relativa, que foi significativamente superior à testemunha geral. O coeficiente de variação $(9,8 \%)$ dá boa precisão ao ensaio. Trabalhos conduzidos por Torres (11), Pilczer e colaboradores (9), assim como outros, conduzidos no Rio Grande do Sul (10), mostram resultados contrários aos aqui obtidos, pois observaram que, no aumento de produção, tanto o salitre-do-chile como o sulfato de amônio apresentaram o mesmo resultado, e se houve algum caso de supremacia este foi observado quando do uso do salitre-do-chile. Essa melhoria de produção, observada pela utilização do sulfato de amônio, talvez seja devida ao solo em que foi conduzido o experimento, por carência de enxofre, embora não tenham sido constatados sintomas de deficiência desse nutriente, em culturas extensivas, conduzıdas na região de onde proveio o solo. 


\section{4 - CONCLUSÕES}

a) A aplicação de nitrogênio ao Latossolo Vermelho Escuro orto induziu acréscimos substanciais na produção de matéria seca e de grãos, pelo trigo.

b) Sobre a produção de grãos, foi a seguinte a escala de influência dos fertilizantes nitrogenados estudados: sulfato de amônio $>$ uréia $>$ salitre-do-chile.

c) Sobre a produção de matéria seca, todos os três adubos nitrogenados se comportaram igualmente.

d) Via de regra, em qualquer dos casos a dose 2 de nitrogênio apresentou resposta quantitativa inferior à da dose 1 .

\section{EFFECT OF DIFFERENT NITROGEN FERTILIZERS ON WHEAT PRODUCTION}

\section{SUMMARY}

The influence of ammonium sulphate, Chilean nitrate, and urea on wheat production was studied in a greenhouse pot experiment using a ortho Dark Red Latosol. The results showed that in the dry matter production any difference was noted among the fertilizers compared; in grain production, however, ammonium sulphate gave the best results.

\section{LITERATURA CITADA}

1. BLANCO, H. G.; VENTURINI, W. R. \& GARGANTINI, H. Comportamento de fertilizantes fosfatados em diferentes condições de acidez do solo, para o trigo, com estudo do efeito residual para a soja. Bragantia 24:261-279, 1965.

2. \& CUIABANO, N. Adubação 24:481-504, 1965 .

3. BOVAY, E.; PUGNAT, C.; SAHLI, B. \& ZWEIFEL, J. Influence du mode de distribution de l' engrais azoté sur le développement et le rendement du froment d' automne dans les conditions de la Suisse Romande. Lausanne, Stations Féderales D'Essais Agricoles, 1961. 18p. (Publication 627) 
4. DEVINE, J. R. \& HOLMS, M. R. J. Field experiments comparing autumn and spring applications of ammonium sulphate, ammonium nitrate and calcium nitrate for winter wheat. J. agric. Sci. 63:69-79, 1964.

5. FERREIRA FILHO, J. C. Cultura do trigo. Rio de Janeiro, Ministério da Agricultura, $1942 . \quad 46 \mathrm{p}$.

6. GARGANTINI, H.; CONAGIN, A. \& PURCHIO, M. J. Ensaio de adubação NPK em cultura de trigo. Bragantia 27:13-27, 1958.

7. HULETT, J. R. A method of selecting profitable nitrogen fertilizer rates for wheat in Eastern Washington and Eastern Oregon. Washington Agricultural Experiment Station, 1968. 12p. (Circular 486)

8. LOCKE, L. F.; ECK, H. V. \& TUCKER, B. B. Wheat fertilizer experiments in Northwestern Oklahoma. Oklahoma State University, 1965 20p. (Bulletin B-640)

9. PILCZER, M. M.; PATELLA, J. F. \& KALCKMANN, R. E. Experimentos de adubação de trigo em Santa Catarina. Pelotas, Instituto Agronômico do Sul, 1956. 42p. (Mimeografado)

10. SERVIÇO TÉCNICO AGRONOMICO DO SALITRE DO CHILE. O cultivo do trigo. São Paulo, 1956. $12 \mathrm{p}$.

11. TORRES, C. B. Adubação do trigo no Rio Grande do Sul. Porto Alegre, Secretaria da Agricultura do Rio Grande do Sul, 1958. $45 \mathrm{p}$. 